\title{
Influência da massa de sementes na emergência de plântulas de feijão-fava (Phaseolus lunatus L.)
}

\author{
Juciely Gomes da Silva ${ }^{1}$, Rayane Ellen de Oliveira Jerônimo ${ }^{2}$, Ramon Quaresma Zeferino $^{3}$, Ariel Roxany da Silva \\ Brasileiro ${ }^{4}$, Andressa Rodrigues do Santos ${ }^{5}$, Rener Luciano de Souza Ferraz ${ }^{6}$
}

Universidade Estadual da Paraíba, ${ }^{1}$ jucielygomes07@ @otmail.com; ${ }^{2}$ rayanneoliveira67@ @ive.com; ${ }^{3}$ ramonqzeferino@yahoo.com; ${ }^{4}$ arielrsb@gmail.com; ${ }^{5}$ andressa440@gmail.com; ${ }^{6}$ ferragroestat@gmail.com.

\begin{abstract}
RESUMO:O feijão-fava possui ampla distribuição no Brasil, com destaque para a região Nordeste, especificamente o estado da Paraíba, um dos maiores produtores da cultura, devido ao seu potencial de adaptação e rusticidade. A utilização de sementes de qualidade é um fator determinante para potencializar a produção, já que estas são responsáveis pelo bom desempenho da cultura. Diante do exposto, objetivou-se realizar teste de germinação para avaliar a interferência da massa na porcentagem de plântulas emergidas, no índice de velocidade de emergência e no tempo médio de emergência de plântulas de feijão-fava do tipo orelha-de-vó preta. A pesquisa foi realizada na casa de vegetação do Centro de Ciências Agrárias e Ambientais da Universidade Estadual da Paraíba. Foram utilizadas 210 sementes adquiridas de um agricultor familiar da região, estas foram divididas de acordo com a massa; T1 sementes leves, T2 médias e T3 pesadas. Cada tratamento foi composto por 7 repetições e cada repetição composta por 10 parcelas, onde foram semeadas 10 sementes em cada repetição; a contagem das plântulas emergidas foi realizada diariamente. Verificou-se que a massa das sementes não apresenta efeito significativo, uma vez que as médias das variáveis se mostraram semelhantes. $O$ fato de a massa não ser uma variável influenciadora na germinação, sugere-se que o agricultor realize a seleção de sementes com base em aspectos comerciais e estéticos.
\end{abstract}

PALAVRAS-CHAVE: Fava orelha-de-vó preta; Qualidade de sementes; Vigor de plântulas.

\section{INTRODUÇÃO}

O feijão-fava (Phaseolus lunatus L.) é uma leguminosa pertencente à família Fabaceae que apresenta elevada diversidade, rusticidade e adaptabilidade, requer pouca umidade e possui maior tolerância ao calor (ADVÍNCULA et al., 2015). A cultura é considerada uma fonte alternativa de alimentação e renda, além de se destacar importante na segurança alimentar e nutricional devido ao fornecimento de proteína vegetal (BARREIRO NETO et al., 2015a). O feijão-fava pode ser utilizado na alimentação humana e pode ser usada também para pastagem, forragem e silagem, bem como no equilíbrio dos ecossistemas, uma vez que a cultura pode ser usada na proteção dos solos, servindo como adubo verde e cultura de cobertura (SOUZA et al., 2016).

No Brasil o cultivo possui ampla distribuição e a região Nordeste destaca-se na produção de 7.416 toneladas, o Estado da Paraíba é o segundo produtor, responsável por 2.181 toneladas produzidas (IBGE, 2014), sendo uma espécie cultivada em quase todas as microrregiões do Estado, destacando-se os municípios de Queimadas, Aroeiras, Campina Grande, Alagoa Nova, Alagoa Grande e Natuba (IBGE, 2015).

O cultivo é realizado tradicionalmente por agricultores dessa região, os quais se utilizam geralmente de sementes crioulas de crescimento indeterminado, seu cultivo é altamente adaptado para a região semiárida, por possuir características agronômicas para desenvolver-se bem em ambientes mais secos (CARMO et al., 2015). O feijão-fava do tipo orelha-de-vó preta é bastante difundido no Estado da Paraíba, tal fato pode estar relacionado à resistência da cultura às pragas e doenças, a sua adaptação a região, à sua produtividade e vigor. No que se refere a sua morfologia, as sementes apresentam coloração branca e preta, sua vagem é achatada e possui até três sementes por vagem e o ciclo da cultura é de 111 a 120 dias (AS-PTA, 2016).

A utilização de sementes de qualidade é um fator determinante como potencializador da produção de feijão-fava, considerando que são as sementes que transportam todo o material genético, além de serem responsáveis pela distribuição uniforme das plantas (AMARO et al., 2015). A qualidade fisiológica da semente é a capacidade em que elas apresentam para desempenhar suas funções essenciais, uma vez que ela influência diretamente no desempenho da cultura, na probabilidade de emergência, na viabilidade e manutenção do vigor, além de proporcionar maior velocidade nos processos metabólicos, alta taxa de crescimento e produtividade (MUNIZZI et al., 2010), estas características podem ser avaliadas rotineiramente pelo teste de germinação, pela emergência das plântulas, pelo índice de velocidade de emergência e pelo tempo médio de emergência (BRASIL, 2009; COELHO JÚNIOR et al., 2014).

Segundo Barreiro Neto et al. (2015b), a variabilidade das sementes comercializadas é extensa e por haver pouca disponibilidade de sementes selecionadas para atender a demanda dos agricultores o uso de sementes é oriundo da própria produção ou obtidas de terceiros. Diante o exposto, objetivou-se realizar teste de germinação para avaliar a interferência da massa das sementes na porcentagem de plântulas emergidas (PPE), no índice de velocidade de emergência (IVE) e no tempo médio de emergência (TME) de plântulas de feijão-fava do tipo orelha-de-vó preta, com o 
SILVA, J. G. et al. Influência da massa de sementes na emergência de plântulas de feijão-fava (Phaseolus lunatus L.). In: II Congresso Paraibano de Agroecologia \& IV Exposição Tecnológica, 2019. Anais Caderno Verde de Agroecologia e Desenvolvimento Sustentável, Pombal, v. 9, n.7, e-7032, 2019.

intuito de buscar melhorias e uniformidade na produção, bem como proporcionar ao agricultor familiar formas de aperfeiçoamento genético e melhor desempenho da sua produção.

\section{MATERIAL E MÉTODOS}

A pesquisa foi realizada na casa de vegetação do Centro de Ciências Agrárias e Ambientais (CCAA) da Universidade Estadual da Paraíba (UEPB), localizado na zona rural do município de Lagoa Seca/PB, nas coordenadas de latitude $7^{\circ} 09^{\prime} \mathrm{S}$, longitude $35^{\circ} 52^{\prime} \mathrm{W}$ e altitude de 634m (SOARES et al., 2017). Para a realização do experimento, foram utilizadas 210 sementes de feijão-fava do tipo orelha-de-vó, estas foram obtidas de um agricultor familiar do município de Lagoa Seca/PB. As sementes foram previamente pesadas e classificadas em relação a massa em três tipos de tratamento, T1: sementes leves $(0,56 \mathrm{~g}$ a $0,82 \mathrm{~g})$, T2: médias $(0,83 \mathrm{~g}$ a $1,07 \mathrm{~g})$ e T3: pesadas $(1,08 \mathrm{~g}$ até $1,33 \mathrm{~g})$.

Após a divisão das sementes em cada tratamento, teve início o processo de semeadura, a profundidade utilizada foi a mesma para todas as sementes, cerca de $3 \mathrm{~cm}$. Cada grupo foi semeado em bandejas plásticas, com medidas de $7,5 \mathrm{~cm} \times 22,1 \mathrm{~cm} \times 30,3 \mathrm{~cm}$, de profundidade, largura e comprimento, respectivamente. $\mathrm{O}$ solo utilizado foi retirado da horta do CCAA e foi colocado para secar, não foi adicionado nenhum tipo de adubo no solo. Em cada bandeja havia um tratamento distinto (T1: sementes leves, T2: sementes médias, T3: Sementes pesadas), cada um comporto por 7 repetições, onde foram semeadas 10 sementes por repetição, totalizando 70 sementes de feijão-fava do tipo orelha-de-vó preta em cada tratamento. Foi utilizado o delineamento inteiramente casualizado (DIC) para a realização a pesquisa (Figura 1A e 1B).

Figura 1. Semeadura de feijão-fava do tipo orelha-de-vó (A) com cerca de $3 \mathrm{~cm}$ de profundidade (B). Lagoa Seca/PB, 2019.
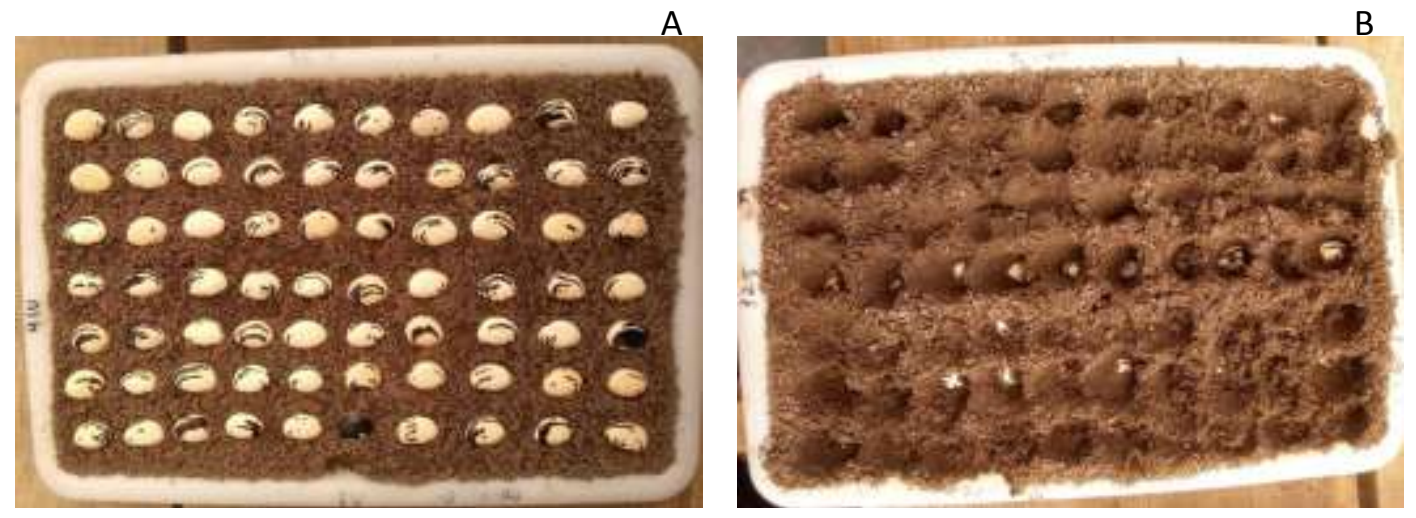

Após a semeadura, o experimento foi irrigado diariamente de acordo com a necessidade de aplicação de água, as avaliações foram realizadas até o $12^{\circ}$ dia de instalação do experimento, com o intuito de verificar a porcentagem de plantas emergidas (PPE \%), o índice de velocidade de emergência (IVE, adimensional) e o tempo médio de emergência (TME, em dias).

As plântulas emergidas foram contadas em intervalos de 24 horas. O cálculo para constatar a porcentagem de plantas emergidas (PPE)foi realizado a partir da contagem das plântulas, sendo $P P E=\left(\frac{N_{2}}{N_{1}}\right) x 100$, onde PPE = porcentagem de plântulas emergidas, $\mathrm{N}_{2}=$ número de plântulas emergidas e $\mathrm{N}_{1}=$ número de sementes semeadas. Para verificar o índice de velocidade de emergência (IVE) registrou-se diariamente o número de plântulas emergidas até o dia que houve estabilização da emergência, este foi calculado através da fórmula proposta por Maguire (1962), a qual é representada pelo $I V E=\left(\frac{100}{N}\right) x \sum\left(\frac{n}{j}\right)$,em que: $\mathrm{N}=$ número de sementes semeadas, $\mathrm{n}=$ número de plântulas emergidas no dia j ( $\mathrm{j}=$ o número de dias após a semeadura (A-AS-SAQUY; CORLETO, 1978). O tempo médio de emergência (TME)foi calculado através da média ponderada do tempo preciso para a emergência das plântulas, proposto por Labouriau e Valadares (1976), $T M E=\frac{\sum_{t}^{n}}{\sum n}$, em que, $\mathrm{n}=$ número de plântulas emergidas e $\mathrm{t}=$ número de dias após a semeadura.

Os dados foram tabulados utilizando-se de planilha eletrônica e posteriormente submetidos a análise de variância (ANOVA) e teste de comparações múltiplas de médias (teste Tukey) ao nível de 5\% de probabilidade de erro. Para processamento das análises utilizou-se do Software para análises estatísticas - Sisvar (FERREIRA, 2014). 
SILVA, J. G. et al. Influência da massa de sementes na emergência de plântulas de feijão-fava (Phaseolus lunatus L.). In: II Congresso Paraibano de Agroecologia \& IV Exposição Tecnológica, 2019. Anais Caderno Verde de Agroecologia e Desenvolvimento Sustentável, Pombal, v. 9, n.7, e-7032, 2019.

\section{RESULTADOS E DISCUSSÃO}

De acordo com a análise de variância, verificou-se que a massa das sementes não apresentou efeito significativo na porcentagem de sementes germinadas (PPE), no índice de velocidade de emergência (IVE) e no tempo médio de emergência (TME), sugerindo que estas variáveis não são diretamente influenciadas por este fator (Figura 1).

Tabela 1. Resumo das análises de variância para a porcentagem de plântulas emergidas, índice de velocidade de emergência e tempo médio de emergência. Lagoa Seca/PB, 2019.

\begin{tabular}{lcccc}
\hline \multirow{2}{*}{ FV } & \multirow{2}{*}{ GL } & \multicolumn{3}{c}{ Quadrados médios } \\
\cline { 3 - 5 } & & PPE & IVE & TME \\
\hline Massa & 2 & $304,76^{\text {ns }}$ & $0,10^{\text {ns }}$ & $6,6 \mathrm{e}-5^{\text {ns }}$ \\
Erro & 18 & $117,46^{\text {ns }}$ & $0,08^{\text {ns }}$ & $5,2 \mathrm{e}-4^{\text {ns }}$ \\
CV $(\%)$ & & 11,79 & 17,49 & 12,34 \\
\hline
\end{tabular}

FV: Fontes de variação, GL: Grau de liberdade, PPE: Porcentagem de plântulas emergidas, IVE: Índice de velocidade de emergência, TME: Tempo médio de emergência.

Resultados semelhantes foram encontrados no estudo realizado por Gomes et al. (2016), a fim de avaliar a eficiência de óleos essenciais na incidência de fungos e interferência na qualidade de fisiológica das sementes de feijãofava, onde os testes de germinação não apresentaram diferenças significativas entre os tratamentos quando avaliados na contagem de plântulas emergidas e no índice de velocidade de emergência, obtendo-se os valores médios variando de 84 a $92 \%$ para primeira contagem, 88 a $92 \%$ de sementes germinadas e para o índice de velocidade da germinação ficou entre 9,4 a 10,0. Em uma pesquisa realizada por Abud et al. (2010), utilizando sementes de cártamos foi possível constatar que as massas das sementes não foram estatisticamente significativas no que se refere a porcentagem de plântulas emergidas, ao índice de velocidade e no tempo médio de emergência. Desse modo, sugere-se que a mobilização de substâncias de reservas e translocações para os pontos de crescimento mostraram-se de forma semelhante (CARVALHO; NAKAGAWA, 2000).

Constatou-se que as sementes de feijão-fava do tipo orelha-de-vó preta quando divididas em tratamentos não apresentaram médias distintas. As sementes consideradas leves apresentam porcentagem média de plântulas emergidas de $84,28 \%$; as sementes consideradas médias apresentam uma taxa de 95,71\%; e as sementes pesadas, obtiveram um valor médio de 95,71\% (Figura 2A). Quando analisada as médias relativas ao índice de velocidade de emergência, as sementes leves apresentaram 1,56; as sementes médias 1,78 e as sementes pesadas, 1,76 (Figura 2B). Em relação ao tempo médio de emergência, constatou-se que as sementes leves levaram 0,1872 dias; as sementes médias, 0,1870; e as sementes pesadas, 0,1818 dias (Figura 2C).

Figura 2. Análise das médias relativas à porcentagem de plântulas emergidas (A), ao índice de velocidade de emergência (B) e ao tempo médio de emergência (C) de feijão-fava do tipo orelha-de-vó em função da massa de sementes. Lagoa Seca/PB, 2019.

A)

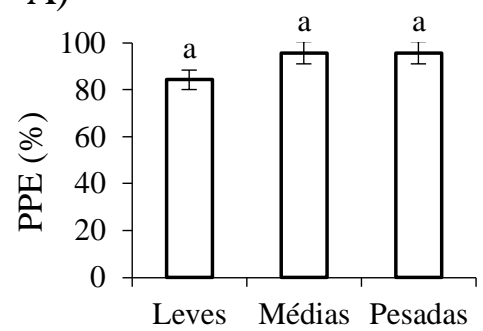

B)

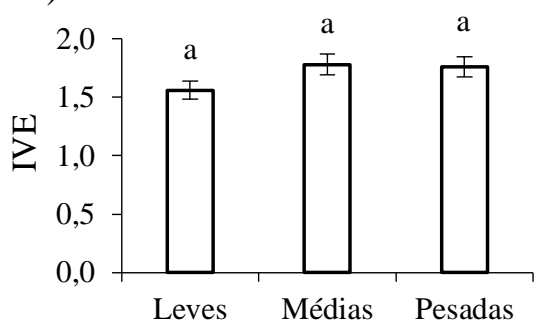

C)

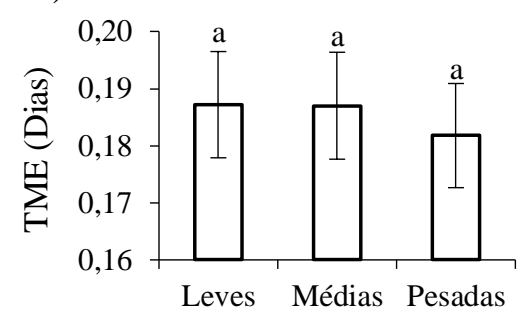

Foi possível constatar que o tamanho das sementes de feijão-fava do tipo orelha-de-vó preta, quando avaliadas de acordo com a massa não apresentam diferenças médias na porcentagem de plântulas emergidas, no índice de velocidade de emergência e no tempo médio de emergência.

Em uma pesquisa realiza por Lima e Carmona (1999), avaliando a influência do tamanho da semente na produtividade de soja de quatro cultivares, os autores observaram que as sementes pequenas sempre ocorreram em menor proporção, em média $12 \%$, seguidas das sementes grandes, em torno de $39 \%$, e das sementes médias, com aproximadamente 49\%, havendo pouca variação entre as cultivares. Lopes et al. (2017), com o intuito de avaliar a produtividade de feijão-fava e milho em consórcio, constataram que a população final de feijão-fava não houve diferença significativa, apresentando-se médias semelhantes independentemente da quantidade de sementes utilizadas na semeadura.

Vale ressaltar a importância de utilização de sementes de boa qualidade na produção, uma vez que tal fator está diretamente relacionado com boa capacidade de germinação e vigor, o que ocasiona um rápido estabelecimento da cultura, permitindo assim uma lavoura uniforme e produtiva (VENDRAME et al, 2015). Em uma pesquisa realizada por Souza et al. (2019), com o intuito de caracterizar e classificar variedades de sementes crioulas de feijão comum no 
SILVA, J. G. et al. Influência da massa de sementes na emergência de plântulas de feijão-fava (Phaseolus lunatus L.). In: II Congresso Paraibano de Agroecologia \& IV Exposição Tecnológica, 2019. Anais Caderno Verde de Agroecologia e Desenvolvimento Sustentável, Pombal, v. 9, n.7, e-7032, 2019.

estado da Paraíba, foi possível constatar que a variedade de feijão gordo apresenta maior massa $(0,40 \mathrm{~g})$ quando comparadas ao feijão preto $(0,18 \mathrm{~g})$.

\section{CONCLUSÕES}

Constatou-se que a massa de sementes de feijão-fava do tipo orelha-de-vó preta, não apresenta efeito significativo na porcentagem de plântulas emergidas, no índice de velocidade de emergência e no tempo médio de emergência de plântulas. O fato da massa não se mostrar uma variável influenciadora na emergência, sugere-se que o agricultor realize a seleção de sementes com base em aspectos comerciais e estéticos.

\section{REFERÊNCIAS}

ABUD, H. F.; REIS, R. G. E.; INNECCO, R.; BEZERRA, A. M. E. Emergência e desenvolvimento de plântulas de cártamos em função do tamanho das sementes. Revista Ciência Agronômica, v. 41, n. 1, p. 95-99, 2010.

ADVÍNCUlA, T. L.; NADAI, F. B.; NOBRE, D. A. C.; FERREIRA, E. N. M. B.; BRANDÃO JÚNIOR, D. S.; COSTA, C. A. Qualidade física e fisiológica de sementes de Phaseoluslunatus L. Revista Brasileira de Ciências Agrárias, v. 10, n. 3, p. 341-346, 2015.

AMARO, H. T. R.; DAVID, A. M. S. S.; ASSIS, M. O.; RODRIGUES, B. R. A.; CANGÚSSU, L. V. S.; OLIVEIRA, M. B. Testes de vigor para avaliação da qualidade fisiológica de sementes do feijoeiro. Revista de Ciências Agrárias, v. 38, n. 3, p. 383-389, 2015.

AS-PTA, Agricultura Familiar e Agroecologia. Sementes da Paixão: Catálogo das sementes crioulas da Borborema. 68p., 2016.

A-AS-SAQUI, M.; CORLETO, A. Effect of seed presowing hardening on seedling emergence of four forage species. Seed Science \& Technology, Zurich, v. 6, p. 701-709, 1978.

BARREIRO NETO, M.; FAGUNDES, R. A. A.; BARBOSA, M. M.; ARRIEL, N. H. C.; FRANCO, C. F. O.; SANTOS, J. F. Características morfológicas e produtivas em acessos de feijão-fava consorciados. Revista Tecnologia e Ciência Agropecuária, v.9, n. 3, p. 23-27, 2015.

BRASIL, Ministério da Agricultura, Pecuária e Abastecimento. Regras para análises de sementes. Brasília, 2009, 399p.

CARMO, M. D. S.; CARVALHO, E. M. S.; GOMES, R. L. F.; LOPES, A. C. A.; CAVALCANTE, G. R. S. Avaliação de acessos de feijão-fava, para a resistência aColletotrichumtruncatum, em condições de folhas destacadas e campo. Revista Summa Phytopathol, v. 41, n. 4, o. 292-297, 2015.

CARVALHO, N.M.; NAKAGAWA, J. Sementes: ciência, tecnologia e produção. 4.ed. Jaboticabal: FUNEP, 2000. $588 \mathrm{p}$.

COELHO JÚNIOR, L. F.; PINTO, M. A. D. S. C.; ARAÚJO, A. V. Emergência de feijão-favas sob efeito de extratos aquosos de diferentes partes vegetativas de juazeiro. Enciclopédia Biosfera, v. 10, n. 19, p. 960, 2014.

FERREIRA, D. F. Sisvar: A Guide for its Bootstrap procedures in multiplecomparisons. Ciência e Agrotecnologia, v.38, n.2, p.109-112, 2014.

GOMES, R. S. S.; NUNES, M. C.; NASCIMENTO, L. C.; SOUZA, J. O.; PORCINO, M. M. Eficiência de óleos essenciais na qualidade sanitária e fisiológica em sementes de feijão-fava (Phaseoluslunatus L.). Revista Brasileira de Plantas Medicinais, v. 18, n. 1, p. 279-287, 2016.

IBGE, Instituto Brasileiro de Geografia e Estatística. Levantamento sistemático da produção agrícola: Pesquisa mensal de previsão e acompanhamento das safras agrícolas no ano civil, v. 1, p. 110, 2015.

IBGE, Instituto Brasileiro de Geografia e Estatística. Produção Agrícola Municipal: Culturas temporárias e permanentes, v. 41, p. 95, 2014.

LABOURIAU, L. G.; VALADARES, M. B. On the germination of seeds of Calotropis procera. Anais da Academia Brasileira de Ciências, Rio de Janeiro, v. 48, p. 174-186, 1976. 
SILVA, J. G. et al. Influência da massa de sementes na emergência de plântulas de feijão-fava (Phaseolus lunatus L.). In: II Congresso Paraibano de Agroecologia \& IV Exposição Tecnológica, 2019. Anais Caderno Verde de Agroecologia e

Desenvolvimento Sustentável, Pombal, v. 9, n.7, e-7032, 2019.

LIMA, A.M.M.P.; CARMONA, R. Influência do tamanho da semente no desempenho produtivo da soja. Revista Brasileira de Sementes, v.21, n.1, p.157-163, 1999.

LOPES, N. S.; SILVA, F. E.; COSTA, M. N. F.; RODRIGUES, W. A. D.; CAMATA, F. T. Produtividade de fava e milho em função do sistema de consórcio em regime de sequeiro na região do cariri-CE. Agrarian Academy, v. 4, n. 8, p. 220, 2017.

MAGUIRE, J. D. Speed of germination aid in selection and evaluation for seedling emergence and vigor. Crop Science, Madison, v. 2, n. 2, p.176-77, 1962.

MUNIZZI, A. et al. Qualidade de sementes de quatro cultivares de soja, colhidas em dois locais no estado de Mato Grosso do Sul. Revista Brasileira de Sementes, v.32, n.1, p.176-185, 2010.

SOARES, C. S.; SILVA, J. A.; SILVA, G. N. Produção de coentro em diferentes espaçamentos dos canais hidropônicos. Pesquisa Agropecuária Pernambucana, v. 22, p. 1-5, 2017.

SOUZA, J. S.; RODRIGUES, L. N.; SOUZA, J. T.; SALES, L. A.; NASCIMENTO, N. F. F. Caracterização morfoagronômica de feijão fava. In: Congresso Técnico Científico de Engenharia e Agronomia, 73, 2016, Foz no Iguaçu. Anais... Foz do Iguaçu: CONTECC, 2016.

SOUZA, L. F.; ARAÚJO, M. S. FERRAZ, R. L. S.; COSTA, P. S.; MEDEIROS, A. S.; MAGALHÃES, I. D. Sementes crioulas de feijão comum (Phaseolusvulgaris L.) para cultivo agroecológico. Revista Verde de Agroecologia e Desenvolvimento Sustentável, v. 14, p. 33-40, 2019.

VENDRAME, R. J.; PESKE, S. T.; GEWEHR, E.; SOARES, V. N. Qualidade fisiológica de semente de soja em função do tamanho da semente e da cultivar. In: MENEGHELLO, G. E.; ALMEIDA, A. S.; VILLELA, F. A.; TUNES, L. V. V. Produção Técnico-Cientifica em sementes-Volume I. Pelotas: Santa Cruz, 2015. Cap. 24, p. 1-16.

\section{AGRADECIMENTOS}

Apoio financeiro: Fundação de Apoio à Pesquisa do Estado da Paraíba - FAPESQ. 